\title{
Pesquisa qualitativa em Educação Matemática a distância: aspectos importantes do uso do Role Playing Game como procedimento metodológico de pesquisa $^{1}$
}

\section{Qualitative research in distance Mathematics Education: important aspects of the Role Playing Game as research methodological procedure}

\author{
Maurício Rosa ${ }^{2}$
}

\begin{abstract}
RESUMO
Este artigo evidencia aspectos do Role Playing Game (RPG), jogo de representação de personagens, que o tornam um importante procedimento de investigação em termos de Pesquisa Qualitativa em Educação (no caso, Educação Matemática) a Distância. Esse jogo foi adotado em uma pesquisa (ROSA, 2008) que estudou as relações estabelecidas entre a construção de identidades online e o ensino e a aprendizagem do conceito de Integral Definida (conceito do Cálculo Diferencial e Integral) em um curso a distância. Assim, a partir dessa investigação que utilizou o RPG jogado a distância, via chat, como procedimento de coleta de dados, discutimos a inserção desse jogo como procedimento metodológico de pesquisa em Educação Matemática a Distância e caracterizamos como esse processo liga-se a questões referentes à Pesquisa Qualitativa nesse novo cenário: o ciberespaço. Logo,
\end{abstract}

1 Este artigo é parte integrante da pesquisa ligada ao Projeto "Educação Matemática On-Line: um Estudo sobre a Constituição de Identidades” - FAPESP (05/56697-3).

2 Doutor em Educação Matemática - Universidade Estadual Paulista (UNESP) Rio Claro. Professor do Programa de Pós-Graduação em Ensino de Ciências e Matemática (PPGECIM), Universidade Luterana do Brasil (ULBRA), Canoas/Rio Grande do Sul, Brasil. E-mail: mauriciomatematica@gmail.com. 
assumimos que adotar o RPG como procedimento de pesquisa favorece tanto o pesquisador, quanto os sujeitos investigados, em termos de mostrarem-se como "diferentes" mesmo sendo "os mesmos" (ROSA, 2008) e isso potencializa a produção do conhecimento matemático, bem como a análise das ações e possibilidades educacionais vislumbradas pelo ser online que se apresenta no ambiente natural apresentado. Também apontamos a adoção do RPG como fator que impele e amplia a concepção pós-estruturalista de Educação que, em ambientes virtuais, cada vez mais, vem destacando e estabelecendo uma amplitude de investigação que transforma esse espaço imaginativo e surpreendente em um ambiente natural de pesquisa.

Palavras-chave: Role Playing Game; metodologia de pesquisa qualitativa; Educação a Distância; Educação Matemática.

\begin{abstract}
This article highlights aspects of the Role Playing Game (RPG), which make an important procedure in terms of research on Qualitative Research in Distance Education (in this case, Mathematics Education). This game was used in a research (ROSA, 2008) that studied the relations between the construction of online identities and teaching and learning of the concept of Definite Integral (concept of Differential and Integral Calculus) in a distance course. Thus, from this investigation that used the RPG (which was played from distance, through chat) as the procedure of data collection, we discuss the inclusion of this game as a methodological procedure of research in Distance Mathematics Education and we characterize how this process connects to Qualitative Research issues in this new scenario: cyberspace. Therefore, we assume that to adopt the RPG as a research procedure favors both the researcher and the subjects investigated in terms of showing themselves as "different" even though "the same" (ROSA, 2008) and this enhances the production of mathematical knowledge as well as the analysis of actions and educational possibilities glimpsed by being online that presents itself in the natural environment presented. Also, we point to the adoption of the RPG as a factor that pushes and extends the poststructuralist conception of education which, in virtual environments, are increasingly emphasizing and establishing a range of research that makes this amazing and imaginative space a natural environment research.
\end{abstract}

Keywords: Role Playing Game; qualitative research methodology; Distance Education. Mathematics Education. 


\section{Introdução}

A discussão sobre metodologia de pesquisa dentro da modalidade Educação a Distância (EaD) começa a acontecer no cenário atual. Em específico, ocorrem questionamentos sobre o ambiente natural de pesquisa, o papel do pesquisador, sobre procedimentos metodológicos e visão de conhecimento (ROSA, 2008). Identificar esses aspectos na modalidade $\mathrm{EaD}$, conforme Borba (2004), faz parte de algumas pesquisas e, da mesma forma, incitou a realização dessa investigação referente ao RPG como procedimento metodológico na $\mathrm{EaD}$, principalmente no que tangencia a Educação Matemática.

Evidenciar o RPG Virtual ${ }^{3}$ como procedimento de pesquisa provém de Rosa (2008), que estudou "como a construção de identidades online em um curso a distância que toma tal jogo como ambiente educacional se mostra aos processos de ensino e aprendizagem do conceito de integral definida". Para Rosa (2008) está na identidade específica em um determinado contexto uma possível articulação para a compreensão da nossa convivência com a realidade ${ }^{4}$ e com o imaginário sobre essa realidade, tendo a Matemática como meio. A investigação sobre quem podemos ser em ambientes virtuais e como reagimos nesses ambientes, então, se fez necessária, pois pôde contribuir para o processo educativo, principalmente no que se refere à Educação Matemática.

Identidades construídas em contextos específicos (cenários) são encontradas em RPGs. No caso da referida pesquisa, para assegurar uma maior possibilidade de imaginação dos envolvidos, utilizamos o RPG Virtual por ser jogado via Web e potencializar a criação destas identidades online (ROSA, 2008), pertencentes às respectivas personagens construídas para o jogo. A necessidade de um alto grau de criatividade para as ações do jogo, promovido pelo anonimato que se liga à própria essência e ludicidade ${ }^{5}$ do RPG Virtual, foi um importante fator para a adoção do RPG como procedimento metodológico do estudo.

Apresentamos, então, este artigo que busca evidenciar: De que forma o jogo RPG pode contribuir com a modalidade de pesquisa qualitativa

3 RPG - Role Playing Game - significa, em uma tradução bem simples, "jogo de interpretação de personagem" ou "jogo de faz-de-conta" e é uma modalidade dentre os jogos que utiliza como base a interpretação e a imaginação dos seus participantes, ou seja, do jogador (que cria uma identidade para si) e do mestre (pessoa responsável em construir a atmosfera do jogo, além de conduzir a história no mesmo) (ROSA, 2004). Em sua versão online, também denominada Virtual, o RPG é jogado a distância via chat (ROSA, 2005).

4 Entendo aqui realidade como realidade mundana discutida em Bicudo e Rosa (2010).

5 Esse aspecto referente à EaD é abordado em Rosa e Maltempi (2006b). 
em termos de Educação (matemática)? Como esse jogo se insere em uma pesquisa que vincula EaD e Educação Matemática e que trabalha com as relações entre a construção de identidades online e o processo de ensino e aprendizagem do conceito de integral definida?

Integral Definida é um conceito previsto, a ser trabalhado, na ementa da disciplina de Cálculo Diferencial e Integral, vista em diferentes cursos de nível superior (no caso desta pesquisa, do Curso de Licenciatura em Matemática, ao qual todos os participantes do estudo estavam vinculados). No entanto, embora o RPG tenha influenciado na produção do conhecimento matemático desse conceito (ROSA, 2008), nos detivemos com a análise do jogo como procedimento metodológico de pesquisa. Logo, o entendimento sobre metodologia de pesquisa na abordagem qualitativa, evidenciada neste estudo, assim como a tomada deste paradigma na modalidade $\mathrm{EaD}$, devem ser discutidos. Buscar esclarecimentos sobre o paradigma qualitativo em pesquisas em Educação, como esse paradigma se mostra, ao que se abre e quais possibilidades revela, faz parte do processo de esclarecimento. Também, levantar essas questões provenientes da pesquisa realizada a distância, em um espaço/tempo específico (ciberespaço), evidenciando suas particularidades quanto às questões de sujeito, de ensino e aprendizagem no mundo cibernético, de potencialidades e necessidades, é uma ação de grande importância para a ampliação do entendimento da $\mathrm{EaD}$ na atual conjectura.

Nessa perspectiva, expandir essas questões inserindo um elemento lúdico para a $\mathrm{EaD}$ e, principalmente, para conteúdos matemáticos vistos, muitas vezes, como de difícil entendimento, faz com que o uso do RPG como procedimento de pesquisa ao mesmo tempo que se constitui prática pedagógica evidencie novas possibilidades tanto para a EaD quanto para a Educação Matemática.

Com isso, justificamos a inserção do RPG como procedimento realizado na pesquisa mencionada e de que forma esse jogo pode contribuir para a pesquisa qualitativa na modalidade da $\mathrm{EaD}$ e para o avanço da própria Educação Matemática a Distância. Para tanto, iniciamos tratando da Pesquisa Qualitativa propriamente dita.

\section{Pesquisa qualitativa: aspectos que estabelecem uma harmonia entre visão de conhecimento e procedimentos metodológicos}

A utilização da metodologia de Pesquisa Qualitativa, em um determinado estudo, entre outras coisas liga-se às escolhas do pesquisador. Entretanto, não são escolhas simples, não são quaisquer escolhas, mas aquelas que dependem 
das vivências, crenças e conhecimentos deste (ALVES, 1991). A partir de seu entendimento do que é Educação, de como se dá a produção do conhecimento e quais são os possíveis caminhos para se perseguir elementos epistemológicos, entre outros objetivos, o pesquisador evidencia um rumo a tomar para o trabalho investigativo. Entretanto, o caminho planejado antes da coleta de dados propriamente dita, na maioria das vezes, toma outras direções, embora mantenha alguns elementos previamente selecionados. Logo, as proposições iniciais pertencentes ao caminho escolhido para se perseguir uma problemática são de suma importância para que se tracem respostas suscetíveis ao mundo científico.

Goldenberg (2000), ao falar de metodologia, revela que se refere a um possível caminho para a pesquisa científica. Ou seja, é o que determina como trabalhar, como investigar o problema proposto. Assim, a metodologia de pesquisa qualitativa, vista como processo de investigação, não se preocupa “[...] com a representatividade numérica do grupo pesquisado, mas com o aprofundamento da compreensão de um grupo social, de uma organização, de uma instituição, de uma trajetória etc." (GOLDENBERG, 2000, p. 14). Assim, preocupa-se qualitativamente com a compreensão deste grupo.

Dessa forma, muitas vezes, por carregar o termo qualitativo, este paradigma de pesquisa sugere uma falsa oposição entre qualitativo e quantitativo. Entretanto, o termo qualitativo serve para dar ênfase a essa abordagem e não para submetê-la a um status de exclusividade. Nesse sentido, Bicudo (2004, p.104, grifo da autora) deixa claro que:

O qualitativo engloba a idéia do subjetivo, passível de expor sensações e opiniões. O significado atribuído a essa concepção de pesquisa também engloba noções a respeito de percepções de diferenças e semelhanças de aspectos comparáveis de experiências, como, por exemplo, da vermelhidão do vermelho, etc.

Está no processo, muito mais do que no produto, a preocupação da pesquisa qualitativa. Ela busca retratar como um determinado problema se manifesta nas atividades e nas interações cotidianas e, assim, o significado que as pessoas dão às coisas e à sua vida são focos de atenção do pesquisador. Isso permite evidenciar questões que retratem o "como" determinado fato acontece. Esse "como" descreve a experiência, de forma a favorecer a compreensão do processo, o qual tem o ambiente natural como fonte direta de dados e, segundo Alves-Mazzotti e Gewandsznajder (2004, p. 160), neste paradigma "[...] o pesquisador é o principal instrumento de investigação". 
Não obstante,

Quando um pesquisador, proveniente de qualquer orientação em pesquisa, põe-se a interrogar sistematicamente um fenômeno, ele já está sendo dirigido pelo que compreende como estando ali para ser pesquisado. Nesta modalidade de estudo, o pesquisador recusa aceitar de início pressupostos ou pré-concepções sobre a natureza do fenômeno investigado. Em vez disso, procura solicitar que os seus sujeitos descrevam em sua própria linguagem como estão vivendo e que experiências estão tendo naquela situação de vida (MARTINS; BICUDO, 1989, p.77, grifo nosso).

Isso nos permite dizer que, em pesquisas qualitativas em educação, por exemplo, divisões existentes entre o sujeito e o objeto, mundo exterior e mundo interior, corpo e alma, servem somente para provocar equívocos. Dessa forma, o objeto de investigação não se apresenta mais como o acontecimento em si, mas como a natureza subordinada à maneira humana de pôr o problema. Logo, inicialmente deve-se situar o fenômeno vivenciado pelos sujeitos. A vivência pode ser traduzida como a experiência percebida de modo consciente por aquele que a executa. Experiência experiencial que "Possui característicos constitutivos, como tempo em que se realiza, impressões, duração, está sempre sendo dirigida para alguma coisa, nunca é estática, há sempre uma relação entre o fenômeno que se mostra e o sujeito que experiencia" (MARTINS; BICUDO, 1989, p.76).

Nessa perspectiva, tanto os participantes quanto o pesquisador são valorizados e passam a estabelecer uma relação de colaboração e, assim, " [...] não se pode, no processo de investigação, deixar de valorizar a imersão do pesquisador no contexto, em interação com os participantes, procurando apreender o significado por eles atribuído aos fenômenos estudados" (ALVES, 1991, p. 55). O pesquisador se faz participante, se faz "sujeito" da pesquisa, na medida em que exerce a ação de interpretar culturas, vivenciando-as a partir de sua racionalidade, instintos, sentimentos, sensações, percepções etc. (CLARETO, 2005).

Também, na pesquisa qualitativa os dados coletados são predominantemente descritivos. Todos os dados são considerados importantes, embora o pesquisador como principal instrumento, às vezes, faça escolhas do que analisar. No entanto, a análise dos dados tende a seguir um processo indutivo, o qual pode ser entendido como aquele em que o pesquisador parte de observações mais livres, permitindo que as dimensões e categorias de interesse emerjam do próprio processo (PATTON, 1986). Isso pode ser entendido pelo que afirma Rivero (2004), ao revelar que os estudos se consolidam basicamente de baixo 
para cima e, por isso, é que são dispensáveis hipóteses antecipadas. Mesmo assim, pode existir um quadro teórico que oriente a coleta e análise dos dados.

Embora percebamos a pesquisa qualitativa conforme apresentado anteriormente, ou seja, um paradigma de pesquisa que valoriza o processo; que pode responder o "como" as coisas acontecem, valorizando seus significados; que busca entender a ação do fenômeno, no ambiente natural a esse; que valoriza o pesquisador como ator protagonista, no decorrer de toda a investigação; que busca enquadrar os resultados provenientes de cada investigação em um quadro teórico discutido em outras pesquisas; que possibilita que o foco e design da pesquisa emerjam do processo no sentido de moldar o que havia sido possivelmente planejado; e que confirma a origem de problemas a serem investigados na prática de quem irá pesquisar; entre outros aspectos, entendemos que não há um consenso, entre os pesquisadores que se inserem no paradigma qualitativo, referente a todas essas questões.

"Na verdade, as pesquisas qualitativas diferem entre si mais pelo grau de estruturação imposto ao design que pela discordância quanto à presença das características citadas" (ALVES, 1991, p. 55). Em relação ao grau de estruturação, podemos afirmar que esse varia entre dois extremos. Um deles está relacionado ao grau máximo de manipulação de estímulos e respostas, ou seja, o grau em que o pesquisador interfere nas condições antecedentes ao fenômeno e a rigidez quanto às categorias a serem analisadas. Esse extremo é representado por experimentos nos quais o pesquisador exerce o maior controle possível sobre as variáveis estranhas e verifica os efeitos disso a partir de relações antecipadas pela teoria.

No outro extremo estaria a investigação "puramente naturalista", na qual não haveria qualquer interferência do pesquisador sobre os antecedentes da situação ou sobre o tipo de resposta a serem consideradas. É evidente que esse tipo extremo é tão virtual quanto o experimento em que todas as condições são controladas (ALVES, 1991, p. 55).

Encaramos, então, que um posicionamento de pesquisador na linha qualitativa não precisa estar nem em um extremo, nem no outro. A pesquisa de Rosa (2008), mesmo possuindo um design emergente, uma vez que vários encaminhamentos foram tomados no decorrer da mesma, estabeleceu "[...] um planejamento inicial, flexível, para não correr o risco de se perder em um emaranhado de dados e não encontrar significado algum para eles" (ARAÚJO; BORBA, 2004, p. 29). Isso possibilitou a identificação inicial de certas teorias e a inserção de outras no decorrer da pesquisa. Os dados, então, apresentaram- 
-se, e foi no planejamento inicial que se encontraram as possibilidades, também iniciais, para o tratamento desses dados, assim como, anteriormente a isso, para a própria coleta desses.

Com isso, entendemos que os aspectos da pesquisa qualitativa tornaram-se coerentes para o contexto da investigação de Rosa (2008), de forma a caracterizar uma relação harmoniosa desse paradigma, com a concepção de conhecimento e com os procedimentos que conduziram todo o processo investigativo.

O estudo foi planejado e, conforme afirmam Araújo e Borba (2004, p. 41), "[...] promovendo uma harmonia entre metodologia de pesquisa, procedimentos metodológicos e concepção de conhecimento [...]". Nesse ínterim, para investigar "como" a construção de identidades online se mostrava, Rosa (2008) optou por meio de suas vivências, crenças e entendimentos pela metodologia de pesquisa qualitativa que possibilita a percepção e compreensão do fenômeno socialmente acordado. Pois, conforme Araújo e Borba (2004, p. 42), "Não é coerente realizar pesquisa de cunho qualitativo e não entender que a verdade que dela se origina é socialmente acordada".

Além disso, compreender como tal construção se mostrava ao ensino e à aprendizagem de integral definida significou, para Rosa (2008), relacionar a concepção de conhecimento à metodologia empregada, visto que entendemos o processo de construção, de um suposto "produto" (a identidade online dada também em processo), como algo significativo ao ensino e aprendizagem de matemática, em específico, de tal conceito. Concebemos que o "ser" liga-se diretamente ao aprender e, enquanto professor, ao ensinar. Diferentes identidades trabalham os conceitos matemáticos de formas diferentes e buscam a compreensão dos mesmos, interligados com o mundo que vivenciam, assim como, com os outros e consigo mesmos.

O processo de construção de identidades online, então, foi explorado e, para isso, os procedimentos se caracterizaram em usar o RPG em um curso de extensão totalmente a distância, intitulado "Construindo o Conceito de Integral Jogando RPG Virtual", no qual havia a necessidade dos participantes construírem uma identidade online mergulhada em um contexto específico, constituído propriamente para estudar o conceito de integral definida.

Desse modo, a harmonia entre metodologia de pesquisa, entendida como uma lógica que orienta o processo de investigação; a visão de conhecimento, inserindo as visões de matemática, Educação Matemática etc.; e os procedimentos para a compreensão legítima de um dado fenômeno se constituíram na pesquisa realizada. Assim, ao investigar o "como" a construção de identidades online se mostra ao ensino e aprendizagem de um conceito do Cálculo Diferencial e Integral de forma qualitativa, ou seja, quando o processo toma destaque no decorrer da investigação, Rosa (2008) estabeleceu uma consonância dos proce- 
dimentos com a visão de conhecimento defendida, a qual também evidencia o processo como o mais significativo à construção de conhecimento. Da mesma forma, a compreensão da existência de identidades múltiplas como composição do ser humano (DELEUZE; GUATTARI, 2004) (concepção pós-estruturalista) estabelece consonância com o jogo RPG Virtual que permite e se utiliza da constituição de várias e diferentes identidades online no decorrer da aventura.

Desse modo, aspectos da $\mathrm{EaD}$ em conjunto com a prática do RPG quando voltados à Educação Matemática indicam interessantes perspectivas para o que denomino Educação Matemática a Distância, a qual toma o mundo cibernético e a ludicidade como importantes aportes à educação por meio da matemática. Entretanto, questões metodológicas relativas à $\mathrm{EaD}$ por si só já se manifestam em pesquisas qualitativas nesta modalidade educacional.

\section{Pesquisa qualitativa em Educação a Distância: questões que se apresentam}

Para nós, entender como se dá o paradigma de pesquisa qualitativa no ciberespaço é uma das questões de grande importância quando o trabalho versa sobre a EaD. Da mesma forma, nesta pesquisa, amplia-se ainda mais a necessidade de compreensão desse paradigma, pois a investigação em questão insere-se no campo da Educação Matemática, ligado a uma proposta que utiliza o jogo RPG como ambiente educacional, ao mesmo tempo em que a constituição desse ambiente se faz procedimento de pesquisa. Tal compreensão é necessária visto que o cenário da Educação a Distância, inserido na Educação Matemática, ainda é muito incipiente. São poucos os estudos neste campo de investigação que, até o momento, discutem metodologia de pesquisa no ciberespaço. Dessa forma, muitas são as perguntas sobre o fazer pesquisa em $\mathrm{EaD}$ que se encontram abertas (BORBA, 2004).

Assim, por exemplo,

[...] ainda não está claro o que significa um "ambiente natural", onde a pesquisa se realiza. A pesquisa qualitativa, e suas origens na Antropologia, sugere a necessidade de trabalharmos em ambientes naturais de Educação [...], mas como lidar com esta desconstrução de nossas experiências de espaço e tempo? (BORBA, 2004, p. 309). 
Da mesma forma, como lidar na EaD com a desconstrução do conceito de identidade que possuíamos na realidade mundana caracterizada pela física clássica? Que sujeitos são esses que participam de pesquisas em ambientes virtuais?

A partir desses questionamentos, entendemos que o design da pesquisa muda, uma vez que as concepções (de quem ou o que são os atores envolvidos: seres humanos, ambiente virtual, oralidade, escrita...) se apresentam com outro teor, diferente daquele que é visto nas pesquisas realizadas em ambientes físicos (realidade mundana).

Tomando a metodologia de pesquisa qualitativa como base e estendendo-a para o âmbito da $\mathrm{EaD}$, percebemos que alguns elementos se mantêm, entretanto, configuram-se de maneira própria. Por exemplo, o paradigma qualitativo valoriza o processo e continua valorizando-o no ambiente a distância, porém em ambientes virtuais cujo suporte técnico não conta com videoconferência, o gesto físico, a expressão facial e o tom de voz não são mais considerados como em ambientes físicos. Nesse sentido, Borba (2004, p. 309) já revela que

[...] temos utilizado apenas análise das "transcrições" da sala de batepapo e listas eletrônicas que, ao contrário da pesquisa usual gravada, não necessitam de transcrições, já que a "fala" já é naturalmente transcrita. Mas entendo que a natureza deste texto produzido é diferenciada, é um misto de fala e escrita [...].

Isso sugere a valorização ainda maior do pesquisador, como ator protagonista do processo, pois esse se encontra no papel do interpretador, o qual se torna potencializado. Entendemos o papel do pesquisador dessa maneira, visto que não há mais registro se não escrito das percepções dos participantes. Os sujeitos da pesquisa, em chats, anunciam seus sentimentos através de palavras capituladas ou entre parênteses, no máximo. Ao invés da percepção via visualização de vídeo, por exemplo, cabe no ambiente a distância (chat) uma interpretação que inter-relacione as significações do pesquisador no decorrer do bate-papo (enquanto participante ou observador) e suas percepções após certo distanciamento dos dados e leitura do chat como um todo, posteriormente.

Assim, o fato do pesquisador não conseguir compartilhar com os participantes das expressões faciais, corporais ou gestuais desses, faz com que a busca em entender a ação do fenômeno, em ambiente natural a esse, como já mencionado, torne-se um grande desafio se pensamos na naturalidade do ciberespaço, sob uma visão dicotômica entre o ser humano e o computador. Entre- 
tanto, quando entendemos a concepção seres-humanos-com-mídias (BORBA; VILLARREAL, 2005) que parte da visão teórica que discute como computadores afetam a cognição humana (TIKHOMIROV, 1981), unida à ideia de coletivo pensante (LÉVY, 2000), na qual a dicotomia entre humanos e tecnologias é "ultrapassada", é possível entender tal ambiente como realmente natural, pois não se encontra desvinculado do próprio ser humano, encontra-se modificado no sentido de ampliar possibilidades de vivências.

Tal concepção identifica a produção de conhecimento em um espaço compartilhado por atores humanos e não humanos. Nessa perspectiva, as mídias encontram-se também no processo de produção do conhecimento, assim como os seres humanos, sem que haja uma separação, nem hierarquia entre eles.

A construção do conhecimento, então, é possível ao "ser" que habita o mundo virtual, se pensarmos que ele pode construí-lo à medida que se constrói como ser humano virtual, no devir de suas ações neste ambiente (DELEUZE; GUATTARI, 2004). Assim, acreditamos que a metodologia de Pesquisa Qualitativa, na modalidade $\mathrm{EaD}$, continua possibilitando que o foco e o design da pesquisa em educação emerjam do processo, no sentido de moldar o que havia sido possivelmente planejado. No entanto, esse design não pode contar com as percepções do corpo físico (quando tratamos de chat), mas com as percepções provenientes do imaginário, da escrita e de outros elementos indissociáveis das tecnologias em questão.

Também, o paradigma qualitativo na pesquisa em EaD confirma a origem de problemas a serem investigados a partir da prática de quem irá pesquisar. No caso de Rosa (2008), buscar entender a $\mathrm{EaD}$ e as questões de aprendizagem vinculadas a um ser humano virtual surgiu da prática desse autor enquanto pesquisador. Compreender a construção de identidades online, de um sujeito coletivo, constituído por identidades que representam papéis sociais e outras tantas passíveis e possíveis de serem criadas foi algo que emergiu da prática de Rosa (2004), enquanto pesquisador em Educação Matemática que investigou o RPG em outro contexto, e isso se transformou em outro grande problema de pesquisa a ser estudado em Rosa (2008).

Além disso, a problemática que apresentamos aqui possibilitou que as questões sobre ambiente natural de pesquisa (o ciberespaço); de participantes desse mundo cibernético - tanto estudantes como pesquisador (identidades online construídas); de conceitos matemáticos envolvidos em um contexto imaginado e específico (aventura no RPG Virtual) estabelecessem especificidades quanto à Educação a Distância sob a perspectiva da Educação Matemática. 


\section{Pesquisa Qualitativa em Educação Matemática a Distância: espe- cificidades e possibilidades}

Destacando o fato que metodologia de Pesquisa Qualitativa não se resume na expressão dos procedimentos adotados na coleta de dados, compreendemos que o processo investigativo possui diversos outros elementos importantes. A começar pela inquietação inicial do pesquisador, a qual possui um contexto específico que deve ser levado em consideração e que desencadeia um processo de busca; passando, no caso da Educação Matemática como região de inquérito, pelas visões de conhecimento, de aprendizagem, de Matemática, de Educação Matemática, de mundo e de ser humano; até chegar às escolhas referentes à teoria que dá embasamento ao estudo, aos procedimentos de coleta e de análise dos dados da pesquisa.

Nesse sentido, Rosa (2008) teve uma história enquanto professor de matemática e um dia como graduando em licenciatura, a qual instigou sua curiosidade quanto à disciplina de Cálculo Diferencial e Integral e que conduziu a uma reflexão quanto ao objetivo principal do processo educativo, a aprendizagem do aluno (ROSA, 2008). Também, saber como a construção de identidades nesse novo ambiente educacional (o ciberespaço) se presentificava nos processos de ensino e aprendizagem de integral definida foi questão perseguida, visto que o autor entende o conhecimento como um processo que pode ser enriquecido a partir da construção de algo significativo para o aluno (Construcionismo ${ }^{6}$ ), no caso, sua identidade online; além de, após se situar no processo emergente, perceber a importância e o significado de conceber o conhecimento como uma produção gradativa de um coletivo pensante, constituído por seres-humanos-com-mídias já que a dicotomia entre homem e computador no processo de aprender se quebra enquanto ser-humano-com-ambiente-virtual. Tal fato foi comprovado, pois não havia como desenvolver a pesquisa enquanto processo, e aí se insere o conhecimento, sem a utilização do ambiente virtual como mídia atuante (ROSA, 2008).

Outro fator significativo para a compreensão da produção do conhecimento matemático se fez no entendimento do ciberespaço como condicionante desta

6 O Construcionismo é uma teoria de aprendizagem criada pelo matemático Seymour Papert na década de 1980. É um constructo teórico proveniente de uma família de filosofias que, segundo Papert (1994), nega a ideia que um bom caminho para a aprendizagem está no aperfeiçoamento da instrução, ou seja, em uma melhor comunicação no "passar" a informação. A construção do conhecimento se dá no desenvolvimento de algo que seja de interesse do aprendiz e que faça sentido a esse. 
produção. Percebemos, então, que o mundo virtual e os seres que o habitam são diretamente responsáveis pela construção de tal conhecimento (BICUDO; ROSA, 2010). Assim, estabelecer significado a partir de um contexto específico foi significativo para entender o conceito de integral definida a partir de Somas de Riemmann. Ou seja, a matemática expressa não se resume nos cálculos e leis propostos em problemas, mas na experiência dessa matemática através da vivência desses problemas.

Calcular a área de uma região de plantação de uma propriedade agrícola, na pele de um agricultor, possui um significado diferente em relação a quem não se insere neste contexto, ou seja, quem não está na pele do mesmo. Compreender a situação por meio da matemática é algo que pode se dar naturalmente quando se participa e se presencia a situação vigente. Embora a definição de integral definida já seja conhecida, o conceito de integral definida pode ser perfeitamente estudado sem que sua definição seja apresentada de antemão. A significação desse conceito percorre problemas semelhantes ao apresentado na aventura proposta na investigação de Rosa (2008) e pode ser explorado de diferentes formas. Tal processo é entendido, então, como matemática.

Do mesmo modo, usar essa matemática para a vida, constituindo uma educação por meio da matemática, é o que consideramos ser Educação Matemática (ROSA; VANINI; SEIDEL, 2011). Processo de compreensão do mundo e de si mesmo, com os outros e consigo.

Além disso, enquanto pesquisa qualitativa que pode responder o "como" as coisas acontecem, valorizando seus significados, foi necessário entender o ambiente em que os fatos foram vivenciados como um ambiente em potencial, no qual se pode desprezar as leis naturais, por exemplo. Com certeza, um fazendeiro não utiliza integral definida para calcular a área de plantação, entretanto, um estudante de matemática com sua identidade online fazendeiro utiliza-a, sem trazer problemas para sua caracterização e trazendo contribuições para a sua produção de conhecimento (ROSA, 2008). O ambiente virtual em que as interações entre os participantes envolvem um conteúdo programático de matemática (no caso, o conceito de integral definida) em um aspecto subjetivo, utiliza a imaginação, a fantasia e o lazer, como fontes enriquecedoras do saber. Isso significa que as possibilidades de interpretação aumentam já que o aspecto lúdico insere-se no contexto, de forma a ser particularmente considerado quando o ambiente se caracteriza por sua ludicidade.

A produção do conhecimento matemático toma novos rumos quando o estudante se mostra a partir de uma identidade online construída por este, pois quem aprende? O estudante ou sua identidade online? Quem percebe, concebe e reflete sobre o conceito em questão? Quem orienta o estudo: o professor ou também a identidade construída pelo mesmo? 
Perguntas como essas só vislumbram as interrogações sobre o ensino e aprendizagem de matemática nesse ambiente cibernético, o qual fundamentalmente só apresenta essas possibilidades por causa da constituição do ambiente educacional escolhido, ou seja, por causa da adoção do RPG Virtual. Nesse sentido, tal adoção é uma ação que, na pesquisa de Rosa (2008), se constituiu como procedimento de pesquisa, conforme a pergunta que foi perseguida.

\section{Role Playing Game virtual como procedimento metodológico de pesquisa - o uso na Educação Matemática a Distância}

Rosa (2008) revela que quando se propôs a investigar como a construção de identidades online se mostrava ao processo de ensino e aprendizagem de integral definida, pensou de antemão em montar um curso de extensão que tomasse esse conceito como premissa. Sabia também que seria completamente a distância, pois o processo em si é indissociável do ciberespaço. Além disso, sua prática com o jogo RPG (ROSA; MALTEMPI, 2003; ROSA, 2004; ROSA, 2005), como mencionado anteriormente, foi a mola propulsora da investigação que se iniciava. Logo, o pesquisador entendia que uma maneira coerente de responder a questão norteadora da pesquisa estava em ministrar um curso cuja estratégia pedagógica fosse a própria execução do jogo, tomando como processo de construção das identidades online a elaboração das fichas de personagem, ação prevista no RPG, e a própria vivência destas no intervalo de tempo constituído pelos encontros síncronos e assíncronos do curso (o jogo).

Dessa forma, apresentamos as etapas do procedimento de pesquisa adotado: o planejamento e execução do curso de extensão (o jogo em si), ou seja, ações traduzidas no próprio curso de extensão e a execução dos encontros realizados no mesmo (a aventura de RPG propriamente dita). Fazemos isso para que haja um entendimento sobre o contexto da pesquisa, assim como a compreensão das escolhas realizadas nesta investigação.

\section{$O$ curso de extensão}

O curso de extensão "Construindo o Conceito de Integral Jogando Role Playing Game Virtual" tinha por objetivo trabalhar o conceito de integral definida por meio do jogo RPG Virtual, o qual é jogado via plataforma de comunicação 
a distância em ambiente virtual. A elaboração do curso, então, se concentrou na possibilidade investigativa das identidades online possíveis de serem construídas no RPG Virtual. A partir disso, o jogo passou a ser o ambiente de ensino e aprendizagem do conceito de integral definida sob uma abordagem lúdica e a distância.

Nessa perspectiva, o curso foi destinado a alunos de Licenciatura em Matemática que não haviam cursado a disciplina correspondente em sua instituição, que possuísse o tópico integral definida na ementa. Embora não trate da formação inicial de professores de matemática em tese, entendemos que ao trabalhar com um grupo de licenciandos em matemática, de certa forma, o estudo de Rosa (2008) também contribui para essa subárea da Educação Matemática.

Assim, além dos participantes serem licenciandos, eles não poderiam e não haviam visto formalmente o conceito de integral definida. Essa escolha foi feita com intuito dos participantes não se encontrarem contaminados com uma forma de conjecturar o conceito de integral definida, por exemplo, só por meio de épsolons e deltas, maneira restrita à matemática acadêmica.

Esse curso de extensão foi coordenado pelo Prof. Dr. Marcus Vinicius Maltempi, foi situado no Departamento de Estatística, Matemática Aplicada e Computação (DEMAC) - UNESP - Rio Claro e vinculado ao GPIMEM. Sua realização aconteceu durante os meses de maio e junho de 2005, computando um total de $40 \mathrm{~h} /$ aula totalmente a distância. Essas horas foram subdivididas em seis encontros via chat (de 31/05/05 a 13/07/05, às terças-feiras, das 19 às 22 horas) e atividades assíncronas, como fóruns de discussão, emails e elaboração de um projeto final.

O processo de inscrição no curso ocorreu pela ordem de chegada, no sentido de completar todas as etapas desse processo, até preencher o número de vagas no prazo previsto para inscrição. Havia oito vagas, devido ao fato de ser seis o número aproximado de jogadores que se estabelece em uma partida de RPG de mesa, o qual é jogado de forma que todos os jogadores e o mestre da partida encontram-se fisicamente presentes em um mesmo local (MARCATTO, 1996; PAVÃO, 2000; RODRIGUES, 2004), além de duas vagas sobressalentes, que não menos importantes, foram adicionadas, conforme Rosa (2008), prevendo os abandonos. Assim, em um primeiro momento o licenciando em matemática que soube do curso em sua instituição de ensino acessou o site e lá encontrou os procedimentos a serem tomados para a inscrição.

Em um segundo momento, o estudante teve que preencher uma entrevista pessoal; ler um texto sobre RPG; ler a sinopse da aventura que iria participar; e construir uma personagem, a partir de uma ficha destinada a isso, como passo

7 <http://demac.rc.unesp.br/marcus/cursos/curso2/index.html $>$. 
inicial para a construção da identidade online que se constituiria no próprio curso; enviando todo esse material por email para o pesquisador (ROSA, 2008) que foi o responsável pelo curso e também participante do mesmo. Assim, somente após o envio do material é que o aluno estaria matriculado no curso e receberia pelo email de sua personagem (o qual constava na ficha) o login e a senha de acesso à plataforma que foi utilizada no decorrer desse. Isso foi um procedimento de grande importância, uma vez que os alunos só se conheciam via sua identidade online, pois seus dados pessoais não foram divulgados até o último encontro efetuado.

A leitura do texto sobre RPG serviu para situar cada um dos estudantes na proposta do jogo, para informá-los sobre a prática do RPG, como era jogado em um ambiente online; o que deveria ser observado no preenchimento da ficha da personagem; a importância em se ler a sinopse da aventura antes de se compor a personagem, uma vez que essa deveria estar relacionada ao contexto em questão; assim como demais dúvidas a respeito da prática em questão. Portanto, a leitura desse texto sugeriu uma ambientação com o RPG, de forma a esclarecer sua prática. No entanto, mesmo havendo o texto com os principais elementos do jogo e da forma de se jogar, foi disponibilizado um email para qualquer tipo de esclarecimento que não fosse contemplado no texto ou mesmo que ainda se caracterizasse objeto de dúvida.

Após a leitura e aquisição de informações sobre o RPG, o estudante passava a ler a Sinopse da Aventura, a qual era elemento chave para que se pudesse criar a personagem que iria se inserir na história. A sinopse caracterizava o contexto no qual o conceito de integral definida seria explorado. Logo, o estudante entrava em contato com tal sinopse intitulada "Um Olhar sobre o Campo", a qual apresentava a seguinte narrativa:

A Sra. Ana Farias Dutra era casada há 20 anos com o Sr. Ivan Porto Dutra que no mês passado sofreu um enfarte e veio a falecer. Ana é uma mulher com pouco estudo, mas com muita força de vontade para viver. Durante os 20 anos de casamento morou na fazenda, ao lado de seu marido, tomando conta exclusivamente das atividades domésticas, deixando as atividades ligadas à agricultura e à pecuária para Ivan. Ana encontra-se grávida e precisa tocar a fazenda para sustento dos três filhos que possui e também desse que está por vir. Assim, precisa de ajuda para entender como proceder tanto na lida do campo, quanto na negociação dos grãos que colhe. Essa é uma tarefa que Ana precisa ultrapassar em um curto intervalo de tempo para sua própria sobrevivência. 
Além disso, outras informações constavam nesse texto, de forma a caracterizar elementos passados que pudessem ajudar no preenchimento da ficha da personagem que deveria ser criada possuindo algum vínculo com esse contexto.

\begin{abstract}
$O$ que aconteceu antes
Ivan adquiriu dinheiro como capataz de uma fazenda no Rio Grande do Sul, na qual aprendeu toda a lida do campo e a plantar soja. Casou-se com Ana e, após esse acontecimento, mudaram-se para outra cidade, onde puderam comprar sua própria propriedade e prosseguir com o plantio de tal grão. Ambos de procedência humilde, criaram três filhos e esperam um quarto, o qual foi concebido sem um planejamento prévio. Ivan nunca se preocupou em ensinar o que sabia sobre o cultivo de soja à mulher, nem aos filhos. Mas, ele e a mulher sempre se preocuparam, providenciando o estudo necessário para seus herdeiros, cada um no nível em que se encontra.
\end{abstract}

O Cenário no qual a aventura se passaria também foi caracterizado, para que cada participante se situasse espacialmente em relação ao local onde várias ações ocorreriam.

\begin{abstract}
Cenário
A história se passa na propriedade rural dos Farias Dutra, no interior do Rio Grande do Sul, a qual se destina ao cultivo de soja, que garante o sustento da família. Em tal local, existe uma casa de madeira com três quartos, uma varanda, uma cozinha colonial, um quarto de banho e uma dispensa para os mantimentos, assim como um celeiro, um paiol e um açude [um rio] ${ }^{8}$. O paiol possui a forma de um prisma retangular, cujas dimensões são iguais a: seis metros de largura, oito metros de comprimento e três de altura. Esse é usado para o armazenamento da soja que se encontra em silos, os quais são guardados no próprio paiol. $O$ açude[rio] contorna a casa, restando uma região de forma irregular para o plantio da soja. A casa ocupa boa parte do terreno e por ter sido construída aos poucos, não foi muito bem planejada.
\end{abstract}

8 Insiro a palavra rio, pois embora tenha se apresentado na sinopse como açude, durante toda a aventura esse elemento do cenário foi tratado e entendido como rio. 
A família possui alguns animais como: galinhas, patos e vacas, assim como, utensílios para o cultivo de soja, tratores e um carro utilizado para ir ao centro da cidade, a Passo Fundo, ou mesmo a Porto Alegre. Os Farias Dutra vivem de maneira simples, no entanto, até o momento não passaram necessidade. A propriedade localiza-se a $20 \mathrm{~km}$ de distância do centro da cidade.

Assim, o texto "Um Olhar sobre o Campo" finalizava-se com o que no RPG é denominado "Chamado à Aventura" (ZANINI, 2003), ou seja, uma situação ou ação que acontece para que as protagonistas (os jogadores) se sintam convidadas a sair da posição estática para ir se aventurar. Tal situação foi apresentada em forma de uma pergunta composta.

\section{Chamado à Aventura}

Como ajudar a Sra. Ana a administrar a propriedade? Quais são os conhecimentos necessários para isso? Matematicamente o que se precisa saber?

A partir desses elementos, os quais caracterizaram a aventura a ser jogada no RPG, foi possível criar cada uma das personagens do jogo, idealizadas por cada um dos participantes. Essa idealização foi o que permitiu a construção, a partir da elaboração das fichas e no decorrer das ações da aventura, das identidades online dos estudantes no curso.

A Ficha da Personagem é, por sua vez, um elemento na prática do jogo RPG. Ela é utilizada para dar contornos iniciais à personagem que será representada no decorrer do jogo. Ela lista os elementos físicos e psicológicos, a história, as posses e a percepção da identidade da personagem, por aquele que a constrói. Tais aspectos identificam a personagem e, ao mesmo tempo, passam por um processo de autoidentificação daquele que os escolhe, ou seja, daquele que começa a construir uma identidade a ser vivenciada na prática do jogo. Tal ficha foi elaborada pelo pesquisador (ROSA, 2008), tomando outras de diferentes sistemas ${ }^{9}$ como base.

A partir do preenchimento da ficha, então, é que o participante foi credenciado na plataforma utilizada, recebendo via email da personagem o login

9 “Sistema de RPG, como são chamados os livros que descrevem 'universos' e regras, têm seu estilo próprio, alguns ressaltando mais o aspecto teatral do jogo, outros priorizando a exatidão (a complexidade) das regras" (MARCATTO, 1996, p. 21) - por exemplo, GURPS. 
e a senha de acesso ao ambiente. Esse procedimento se deu como mais um lembrete que quem participaria do ambiente era a personagem criada e não o licenciando em matemática que se matriculava naquele instante, embora seja difícil separá-los com exatidão. Esse lembrete também constava na página de acesso à plataforma de $\mathrm{EaD}$ utilizada.

Do mesmo modo que os participantes, Rosa (2008) também criou, enquanto pesquisador inserido no curso como mestre da aventura, uma outra identidade online tornando-se uma personagem jogadora. Ou seja, além de representar todas as outras identidades cabíveis ao mestre da partida, a criação de uma personagem-jogadora o permitiu permanecer anônimo como um aluno, igualando-o em nível hierárquico ${ }^{10}$ a todos os outros participantes e contribuindo, assim, para a estratégia colaborativa ${ }^{11}$.

A plataforma de Educação a Distância utilizada foi o ambiente TelEduc ${ }^{12}$. Suas ferramentas foram utilizadas, entre outras coisas, para postar endereços (links) da Web contendo diversas informações sobre Agronomia ${ }^{13}$ (plantação de trigo, espaço entre canteiros, estações apropriadas para a plantação,...) e sobre Cálculo Diferencial e Integral. Também, no decorrer da aventura foi necessário, a partir das ações encontradas nessa, inserir um site de conversão de medidas ${ }^{14}$, contendo informações sobre esse assunto. Além dos links para esses sites também foram postados um modelo de ficha da personagem; uma tabela de elementos básicos para construção de aventuras de RPG; endereços de download de dois softwares, um de cálculo (MUPAD - CAS) (BORTOLOSSI, 2002) e um de controle remoto (ULTRA - VNC) (ARAÚJO; BERTO, 2004), para uma eventual utilização no decorrer do curso.

Nessa plataforma havia também os mapas da fazenda. Imagens criadas no software Arcon versão 5.0 $0^{15}$, que possibilitaram a visualização do cenário da aventura, ultrapassando a descrição pura desse. Tais imagens foram fundamentais durante toda a aventura, pois possibilitaram a percepção do ambiente, no qual as ações ocorriam.

10 Embora a identidade física do mestre também não tenha sido revelada, eu acreditava que poderia haver certo rótulo quanto à figura do mestre, vinculando-a à do professor.

11 Para maiores esclarecimentos sobre o aspecto colaboração em uma prática pedagógica de matemática com o uso de RPG ver Rosa e Maltempi (2006a).

12 Tal ambiente é de distribuição livre e está disponível em: $<$ http://www.nied.unicamp.br $>$.

$13<$ http://www.cnpt.embrapa.br/sist-prod/soja04/>; $<$ http://www.seprotec.com.br/prod_soja. asp>.

$14<\mathrm{http}: / /$ www.imoveisvirtuais.com.br/medidas.htm>.

15 "Software de Arquitetura e Engenharia Civil comercializado pela empresa Pini Engenharia, disponível na versão demo em http://www.pini.com.br" (AZEVEDO, 2006, p. 2 - nota de rodapé). 
Figura 1: Imagem geral da fazenda - inclinação para a direita

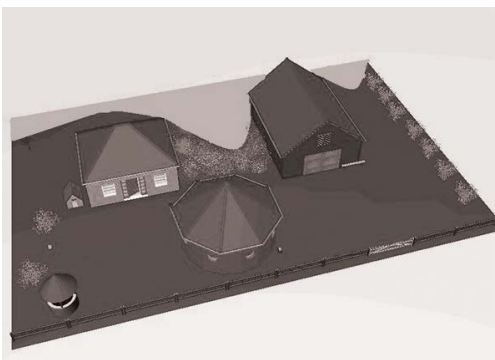

Figura 2: Imagem geral da fazenda - visão frontal

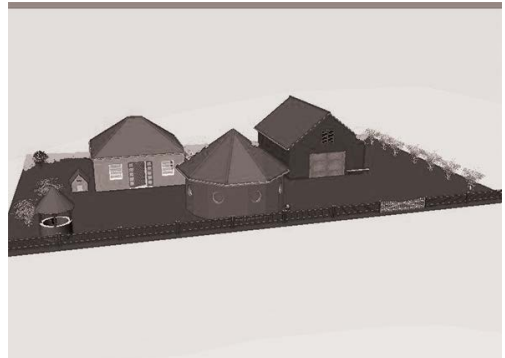

É possível perceber, à esquerda, a casa dos Farias Dutra; à direita nas figuras, o celeiro e, mais à frente, localizado centralmente, o paiol da propriedade. Entre esses três elementos, podemos visualizar a região de plantação. Essa pode ser melhor visualizada na Figura 3, que traz uma visão aérea da propriedade. Assim, a área de plantação vista superiormente fica, nesta imagem, abaixo do rio, sob uma curva formada por este.

Figura 3: Visão aérea da propriedade dos Farias Dutra

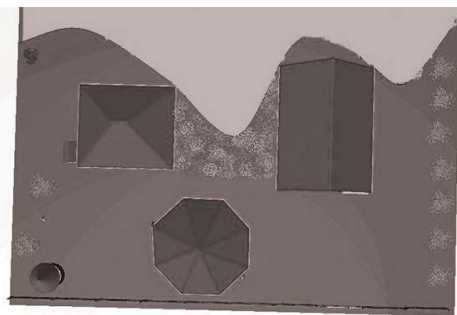

Figura 4: Imagem geral da fazenda - inclinação para a esquerda

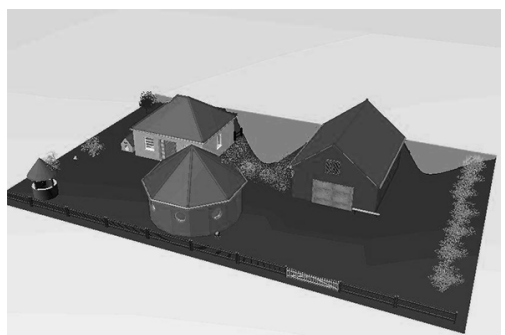

A plataforma TelEduc atuou de forma a armazenar os dados, servir de meio de interação para o RPG Virtual, possibilitar a hipertextualidade de informações, entre outros aspectos, que são fatores que constituem a Educação Matemática a Distância. Sem a presença da mídia informática, a comunicação não seria possível e a caracterização da identidade online seria prejudicada pela ausência de anonimato, se o ambiente de interação fosse fisicamente constituído, por exemplo.

Assim, passamos a identificar os encontros virtuais que aconteceram semanalmente, de forma a caracterizar o que aconteceu em cada um deles, com intuito de trazer, no plano geral, uma visão do processo. 


\section{Os encontros}

O curso teve seis encontros, com duração de três horas cada, os quais constituíram a aventura de RPG proposta. Nesse sentido, cada encontro teve sua relevância e fez parte do processo de construção das identidades online no intervalo do curso.

A partir do primeiro encontro, coube ao pesquisador tornar-se o mestre da partida, responsável por desenvolver a aventura já iniciada e que continuou sendo construída por influência de diferentes pontos de vista (os dos jogadores). $\mathrm{Na}$ aventura ocorreram situações que puderam levar a todos a discutir, refletir, expressar e depurar questões relativas à integral definida, as quais estiveram presentes na própria história estabelecida, por meio do metaenredo ${ }^{16}$ da aventura. Ou seja, tais questões estão presentes no nosso cotidiano (local de inspiração para o desenvolvimento da aventura, pois o cenário inicial apresentado esteve centrado em uma situação possível, imaginada, de acontecer na "realidade mundana" ${ }^{17}$ ), porém, não explicitamente. No $1^{\mathbf{0}}$ Encontro $(31 / \mathbf{0 5} / \mathbf{0 5})$ - Sentindo a Atmosfera do Jogo, aconteceu o que se chama de ambientação, em relação às identidades online que ali se apresentavam; ao cenário virtual da fazenda em si; assim como às conexões existentes entre cada personagem e o contexto da aventura, perpassando a inserção do problema de Dona Ana (chamado à aventura). No $2^{\circ}$ Encontro (07/06/05) - O Problema da Área de Plantação, após o sepultamento do Sr. Ivan, o problema de Dona Ana e a solicitação de ajuda a todos que se encontravam na fazenda foram concretizados. Ela precisava saber como continuar o cultivo de soja, como plantar, quanto plantar, quanto de semente seria necessária. Assim, o grupo percebeu que para responder isso a ela era necessário calcular a área da região de plantação da propriedade dos Farias Dutra. $O 3^{\circ}$ Encontro (14/06/05) - O Conhecimento Empírico e suas Relações com o Científico-matemático apresentou diversos subterfúgios para a ação de plantar sem que necessariamente se calculasse a área. Já o $4^{\circ}$ Encontro (21/06/05) - Um Mix de Percepções e Saberes, problematizou ideias iniciais, que partiram do conhecimento empírico, tomando aspectos da matemática. O $5^{\circ}$ Encontro (28/06/05) - A Identificação Condiciona o Aprender, apresentou um coletivo entre as identidades online, entre as quais uma delas era conduzida pelo mestre como jogador. Na ação de mensurar distâncias para evidenciar a

16 O metaenredo é constituído pelas ações que expressam, neste caso, o conteúdo matemático, mas que são produzidas a partir de ações a serem executadas no decorrer do enredo da aventura.

17 Tomo como "realidade mundana" o ambiente em que vivemos, com diferentes profissões, diferentes áreas de conhecimento etc. Nesse, não há elementos que fantasiem o ambiente como fadas, magos, elfos etc., os quais são comuns em algumas aventuras de RPG. 
função que a curva representava se apresentou a ideia de intervalo representado entre a casa e o celeiro, que foi outra ação aparente nesse encontro. Por fim, o $6^{\circ}$ Encontro (05/07/05) - A Linguagem Matemática no Virtual, alguns problemas. A Matemática e outros Problemas, uma possibilidade evidenciou a percepção das dificuldades de expressão e utilização da linguagem matemática no chat. Entretanto, contribuiu muito para a continuidade da aventura apresentada para outros rumos, outros problemas matemáticos vinculados ao conceito de integral definida, bem como outros conceitos.

Ao passar por essa experiência em Educação Matemática a Distância, então, Rosa (2008) indica algumas considerações sobre a utilização do RPG Virtual como procedimento metodológico de pesquisa, as quais conduzem a uma visão particular em relação ao ensino e aprendizagem de Matemática, no caso, o conceito de integral definida nesse ambiente cibernético e lúdico.

\section{Aspectos importantes sobre o RPG virtual em uma pesquisa liga- da à Educação Matemática a Distância - a análise do jogo}

Considerando a pesquisa em Educação Matemática a Distância que foi desenvolvida, percebemos que existem aspectos que fazem o RPG tornar-se ator proeminente no cenário em questão. Em relação à $\mathrm{EaD}$, entendemos que trabalhar com o RPG permite que o estudante seja quem ele deseja ser no ambiente educacional constituído. Isso seria possível sem o RPG, em outra proposta que utilizasse o chat, por exemplo. Entretanto, o jogo potencializa esse "ser" outro, que é "você" mesmo, de maneira contextualizada e natural, pois a aventura do RPG acontece em um ambiente que é natural à própria aventura. Esse "ser" virtual abre possibilidades de discussão, reflexão, descrição, aprendizagem, entre outras ações, que não seriam possíveis na pele de estudantes encarnados em um corpo próprio, habitantes em uma realidade mundana (BICUDO; ROSA, 2010). Abre possibilidades para que os estudantes se mostrem como eles acharem que devem se mostrar, como quiserem, como um "ser" em con-junto ao ambiente e que se desenvolve ao mesmo tempo em com-junto com esse "ser" virtual (BORBA; VILLARREAL, 2005).

O ambiente educacional constitui-se naturalmente (BORBA, 2004), assim como o processo educativo em tal ambiente. No entanto, é possível que se questione a naturalidade de um mundo cibernético construído, em contrapartida a salas de aula, com lousa, giz e um professor passando informação. Entretanto, seria esse (sala de aula tradicional), da mesma forma, um ambiente natural à educação? Não seria também um ambiente construído? Porém, há mais tempo? 
Compreendo que a naturalidade do ambiente se dá no se constituir o ambiente em com-junto com quem o habita. $\mathrm{O}$ ambiente educacional se faz na ação humana de educar, a partir de uma intencionalidade (MARTINS; BICUDO, 1989), que é humanizadora. A EaD, da mesma forma, possui ambientes educacionais naturais, mas com o RPG a EaD se sustenta de uma naturalidade implícita à criação de cada um dos inúmeros cenários de aventuras pedagógicas. Cada aventura é propícia ao objetivo pedagógico estabelecido previamente, no entanto, surpreende e se torna cabível a um amplo leque de possíveis explorações. Isso potencializa a diversidade de ambientes educacionais virtuais que se fazem naturais no vivenciar de cada um deles (BORBA, 2004), em com-junto com quem o habita, pois a criação de diferentes personagens, possuidoras de diferentes identidades, também é diversificada na adoção do RPG como prática pedagógica e, no caso, como procedimento de pesquisa ao mesmo tempo.

Os "sujeitos" de pesquisa, então, quem são? Eles são quem desejam ser, são quem e como se mostram ser e, assim, naturalmente criam seu ambiente, o qual no RPG é delineado previamente no cenário da aventura, mas que só se presentifica quando há a presença de quem o habita. Nesse sentido, as ações desta presença no RPG (ROSA; MALTEMPI, 2007) emergem no decorrer da aventura e, do mesmo modo, as ações do pesquisador que investiga um tópico específico também emergem dessas outras ações tomadas pelas identidades que se encontram no jogo (ALVES, 1991). A ação de investigar também se torna um jogo, a pesquisa se faz jogo no momento em que se trabalha o tempo todo com o inesperado, pois os procedimentos em direção a um conceito matemático, por exemplo, surgem das ações tomadas pelas personagens do RPG durante o jogar (ARAÚJO; BORBA, 2004).

Também, a percepção dos movimentos, do corpo das personagens, das expressões faciais, etc. não são vistas pelos olhos do corpo do pesquisador, mas são vistas pelos olhos de sua personagem, a qual percebe movimentos de outrem (também personagem). A percepção aí encontra outra dimensão e busca na imaginação e visualização textual seus aportes sensoriais (ROSA, 2008).

Todo o processo é valorizado no ato de pesquisar (GOLDENBERG, 2000). Da mesma forma, na pesquisa em EaD isso também acontece. Entretanto, quando se utiliza o RPG, esse processo é outro, pois o jogo possibilita que se tenha um ambiente natural específico (seja uma propriedade agrícola, um hospital, uma escola, o espaço sideral, etc.) e sujeitos virtuais criados (múltiplas identidades) (DELEUZE; GUATTARI, 2004). Embora não se elimine a necessidade de um ambiente no qual há um computador conectado a uma rede elétrica, de comunicação mundial e de um ser corpóreo encarnado que se encontra em frente a essa mídia, o ato de criar, imaginar, vivenciar um outro que se mostra a partir de minhas concepções, apresenta um processo que dá condições a uma dimensão cognitiva própria, fluida, rizomática (DELEUZE; GUATTARI, 2004). Essa dimensão que 
existe em função do ciberespaço é moldada por ele em todos os seus aspectos.

Assim, enquanto procedimento de pesquisa, o RPG possibilita a expansão das características imaginativas, criativas e lúdicas do processo de investigação em educação. Isso ocorre quando ao criar as personagens do jogo, cujas identidades online vão sendo construídas à medida que essas vivem no mundo cibernético igualmente constituído, os participantes e o pesquisador se mostram como desejam mostrar-se, atuando, agindo e vivendo de maneira a serem atores e autores do processo, todo o tempo. Essa atuação, no caso da Educação Matemática, permite que se estudem conceitos matemáticos, muitas vezes vistos como complexos no ambiente educacional tradicional, de forma natural. De modo que cada estudante pode vivenciar, presenciar e evidenciar significados para esses conceitos que vão além de regras, fórmulas ou simbologias. Esses conceitos se abrem por meio de planos e personagens conceituais (DELEUZE; GUATTARI, 2005).

Enquanto pesquisa, o uso do RPG permite que a investigação das relações entre esse "mostrar-se" como aluno ou professor e o "mostrar-se" como agricultor, fazendeiro, jornalista, prostituta ..., e tantos outros quanto se queira, evidencia uma relação com conceitos matemáticos, éticos, políticos, culturais, econômicos, educacionais, etc. de maneira diferenciada. A hierarquia muitas vezes criticada em sala de aula, na qual o professor é a pessoa detentora do saber e o transmite, assim como o aluno é quem aprende e só recebe as informações, modifica-se. Pois, quem é quem no RPG? Quem é o professor? Quem é o aluno? O operário, o motorista, a dançarina, a própria professora?

O RPG abre, então, a possibilidade de se investigar essas relações que permeiam processos educacionais nos quais a colaboração, por exemplo, é destacada. Abre possibilidades para se discutir o que se aprende? Como se aprende? Quem aprende? Assim como se há ensino? Como se ensina? Quem ensina em ambientes como o apresentado neste estudo? Isso faz com que o campo de pesquisa em EaD e, no caso, sob o espectro da Educação Matemática, estabeleça diferentes rumos quando estamos tratando de um novo espaço/tempo que se apresenta como ciberespaço.

\section{Considerações finais}

O RPG como procedimento de pesquisa pode, então, favorecer tanto o pesquisador/professor quanto os sujeitos investigados, em termos de mostrarem-se como "diferentes" mesmo sendo "os mesmos". Afirmamos isso, pois, para nós, esse ato (utilizar o RPG na pesquisa em $\mathrm{EaD}$ ) potencializa a pesquisa em 
Educação Matemática, assim como a própria produção do conhecimento matemático. Em relação à pesquisa, para o pesquisador, o uso do RPG abre ainda mais o sentido da vermelhidão do vermelho (BICUDO, 2004), ou seja, a forma de se atribuir significado ao que se tem no mundo (cibermundo), por meio das identidades online presentificadas. Da mesma forma, amplia as possibilidades de produção do conhecimento matemático, pois esse procedimento de pesquisa também engloba noções a respeito das percepções do ser online em relação à matemática vivida no ciberespaço.

Não obstante, a análise das ações e possibilidades educacionais vislumbradas pelo ser online, que se apresenta no ambiente natural apresentado, possibilita-nos dizer que a adoção do RPG como procedimento de pesquisa impele e amplia a concepção pós-estruturalista de Educação. Isso acontece pelo fato que, em ambientes virtuais, cada vez mais, temos que destacar que a construção do conhecimento acontece em fluxos, nos quais o "ser" que habita o mundo virtual é múltiplo (DELEUZE; GUATTARI, 2004), de forma a ser-com, pensar-com e saber-fazer-com-o-ciberespaço (ROSA, 2008), ou seja, torna-se um dos seres-humanos-com-mídias (BORBA; VILLARREAL, 2005). Assim, pensamos que ao construir o seu personagem, cada estudante pode construí-lo à medida que se constrói como ser humano virtual, no devir de suas ações neste ambiente (DELEUZE; GUATTARI, 2004) produzindo conhecimento matemático.

\section{Agradecimentos}

Agradeço ao Prof. Dr. Marcus Vinicius Maltempi - UNESP - Rio Claro (SP), à Profa. Dra. Andréia Maria Pereira de Oliveira - Universidade Estadual de Feira de Santana (BA) e ao Prof. Ms. Vinícius Pazuch (ULBRA) pelos excelentes comentários feitos neste artigo.

\section{REFERÊNCIAS}

ALVES, A. J. O planejamento de pesquisas qualitativas em educação. Cadernos de Pesquisas. Fundação Carlos Chagas. São Paulo: Cortez, n. 77, p. 53-61, 1991.

ALVES-MAZZOTTI, A. J.; GEWANDSZNAJDER, F. O método nas ciências naturais e sociais: pesquisa quantitativa e qualitativa. São Paulo: Pioneira, 2004. 
ARAÚJO, A.; BERTO, A. F. B. Uma investigação sobre o software para o auxílio a ambientes educacionais a distância. Trabalho de Conclusão de Curso (Bacharelado em Ciência da Computação) - EEP/ FUMEP, Piracicaba, 2004.

ARAÚJO, J. L.; BORBA, M. C. Construindo pesquisas coletivamente em educação matemática. In: BORBA, M. C.; ARAÚJJO, J. L. (Org.) Pesquisa qualitativa em educação matemática. Belo Horizonte: Autêntica, 2004. p. 25-45.

AZEVEDO, J. L. A. Trabalhando conceitos matemáticos a partir do uso das tecnologias informáticas via projetos. In: ENCONTRO BRASILEIRO DE ESTUDANTES DE PÓS-GRADUAÇÃO EM EDUCAÇÃO MATEMÁTICA, 10., 2006, Belo Horizonte - Conhecimento e Inclusão Social. Anais... Belo Horizonte: UFMG; Faculdade de Educação, 2006. 1 CD-ROM.

BICUDO, M. A. V. Pesquisa qualitativa e pesquisa qualitativa segundo a abordagem fenomenológica. In: BORBA, M. C.; ARAÚJO, J. L. (Org.). Pesquisa qualitativa em educação matemática. Belo Horizonte: Autêntica, 2004. p. 99-112.

BICUDO, M. A. V.; ROSA, M. Realidade e cibermundo: horizontes filosóficos e educacionais antevistos. Canoas: Editora da ULBRA, 2010.

BORBA, M. C. Dimensões da educação matemática a distância. In: BICUDO, M. V.; BORBA, M. C. (Org.). Educação matemática: pesquisa em movimento. São Paulo: Cortez, 2004. p. 296-317.

BORBA, M. C.; VILLARREAL, M. E. Humans-with-media and the reorganization of mathematical thinking: information and communication technologies, modeling, visualization, and experimentation. New York: Springer Science, 2005.

BORTOLOSSI, H. J. Cálculo diferencial a várias variáveis: uma introdução à teoria de otimização. Rio de Janeiro: Editora PUC-Rio; São Paulo: Loyola, 2002.

CLARETO, S. M. Etnografias e pesquisas interpretativas: crises da modernidade e enfrentamentos de seus impactos. In: SEMINÁRIO INTERNACIONAL DE PESQUISA E ESTUDOS QUALITATIVOS, 2., 2005, Bauru. Anais eletrônicos... Bauru, SP: Universidade do Sagrado Coração, Sociedade de Estudos e Pesquisa Qualitativos, 2004. Disponível em: < http://www.sepq.org.br/livros.htm>. Acesso em: 08/09/2006.

DELEUZE, G.; GUATTARI, F. O que é filosofia? 2. ed. Tradução: Bento Prado Jr. E Alberto Alonso Muñoz, 2005.

. Mil platôs: capitalismo e esquizofrenia, vol. 1. Tradução de Aurélio Guerra Neto e Célia Pinto Costa, 2004.

GOLDENBERG, M. A arte de pesquisar: como fazer pesquisa qualitativa em Ciências Sociais. 4. ed. Rio de Janeiro: Editora Record, 2000.

LÉVY, P. A inteligência coletiva: por uma antropologia do ciberespaço. Tradução: Luiz Paulo Rouanet. 3. ed. São Paulo: Edições Loyola, 2000. Tradução de: L'intelligence colective. Pour une anthropologie du cyberspace. Paris: Éditions La Découverte, 1994.

MARCATTO, A. Saindo do quadro. São Paulo: A. Marcatto, 1996. 
MARTINS, J; BICUDO, M. A. V. A pesquisa qualitativa em psicologia: fundamentos e recursos básicos. São Paulo: Moraes, 1989.

PAPERT, S. Instrucionismo versus Construcionismo. In: PAPERT, S. A máquina das crianças: repensando a escola na era da informática. Porto Alegre: Artes Médicas, 1994.

PATTON, M. Q. Qualitative evaluation methods. Beverly Hills: Sage Publications, Inc. 1986.

PAVÃO, A. Aventura da leitura e da escrita entre mestres de Roleplaying Games (RPG). São Paulo: Devir, 2000.

RIVERO, C. M. L. A Etnometodologia na pesquisa qualitativa em educação: caminhos para uma síntese. In: SEMINÁRIO INTERNACIONAL DE PESQUISA E ESTUDOS QUALITATIVOS, 2., 2004, Bauru. Anais eletrônicos... Bauru, SP: Universidade do Sagrado Coração, Sociedade de Estudos e Pesquisa Qualitativos, 2004. Disponível em: $<$ http://www.sepq.org.br/livros.htm>. Acesso em: 08/09/2006.

RODRIGUES, S. Roleplaying Game e a pedagogia da imaginação no Brasil: primeira tese de doutorado no Brasil sobre o roleplaying game. Rio de Janeiro: Bertrand Brasil, 2004.

ROSA, M. A construção de identidades online por meio do role playing game: relações com o ensino e aprendizagem de matemática em um curso á distância. Tese (Doutorado em Educação Matemática) - UNESP, Rio Claro, 2008.

ROSA, M. Role Playing Game (RPG) Virtual: uma perspectiva lúdica para a educação matemática a distância (EmaD). In: CONGRESSO INTERNACIONAL DE ENSINO DE MATEMÁTICA, 3., 2005, Canoas - Anais... Canoas: Universidade Luterana do Brasil, 2005. 1 CD-ROM.

Role playing game eletrônico: uma tecnologia lúdica para aprender e ensinar matemática. Dissertação (Mestrado em Educação Matemática) - UNESP, Rio Claro, 2004.

ROSA, M.; MALTEMPI, M. V. The presence in the cyberspace as a facet of the construction of online identities in a definite integral course. In: PSYCHOLOGY ON MATHEMATICS EDUCATION, 31., 2007, Seoul. Anais... Seoul: Group for the Psychology of Mathematics Education, 2007. 1 CD-ROM. (no prelo)

. Realização de projetos a distância: contribuições da colaboração à Educação Matemática. In: SIMPÓSIO DE EDUCACIÓN MATEMÁTICA, 8., 2006, Buenos Aires - Anais ... Buenos Aires: Universidad Nacional de Luján; Universidad Nacional de Tres de Febrero; Edumat, 2006a. 1 CD-ROM.

. The seen playfulness as aspect of the distance education. In: ANNUAL IRMA INTERNATIONAL CONFERENCE, 17., 2006, Washington-Proceedings ... Washington: Idea Group Publishing, 2006b. 1 CD-ROM. 
. RPG Maker: uma proposta para unir jogo, informática e Educação Matemática In: SEMINÁRIO INTERNACIONAL DE PESQUISA EM EDUCAÇÃO MATEMÁTICA, 2., 2003, Santos. Anais... Santos: SBEM - Sociedade Brasileira de Educação Matemática, 2003. 1 CD-ROM.

ROSA, M. VANINI, L. SEIDEL, D. J.). Produção do conhecimento matemático online: a resolução de um problema com o ciberespaço. Boletim GEPEM. Rio de Janeiro: Universidade Federal Rural do Rio de Janeiro, n. 57, 2011.

TIKHOMIROV, O. K. The psychological consequences of computerization. In: WERTSCH, J. V. The concept of activity in Soviet Psychology. Tradução de: James V. Wertsch. New York: M. E. Sharpe, 1981. Tradução da Língua Russa. Soviet Copyright Agency, 1979.

ZANINI, M. C. Oficina Criando uma Aventura Paradidática. Disponível em: <http:// www. simposiorpg. com.br/textos.htm>. Acesso em: 23/08/2003.

Texto recebido em 10 de outubro de 2009.

Texto aprovado em 15 de abril de 2010. 